\title{
The pleiotropic effect of TRAIL on tumor-like synovial fibroblasts from rheumatoid arthritis patients is mediated by caspases
}

\author{
R Audo ${ }^{1}$, B Combe ${ }^{1,2}$, B Coulet ${ }^{3}$, J Morel ${ }^{1,2,4}$ and M Hahne ${ }^{*, 1,4}$
}

The tumor necrosis factor (TNF)-related apoptosis-inducing ligand (TRAIL) has gained much attention as a possible therapeutic reagent for the treatment of tumors, as TRAIL was originally described to induce apoptosis specifically in cancer cells, but not in normal cells. Fibroblast-like synoviocytes (FLS) in rheumatoid arthritis (RA) patients exhibit tumor-like features and we have described earlier that TRAIL induces apoptosis only in a subset of RA FLS, but an induction of proliferation in the surviving cells. This observation corresponds to the pleiotropic effects of TRAIL observed on primary human tumor cells. Here, we describe that the PI3 kinase/Akt-signaling pathway, but not that of the MAP kinases ERK and p38, protects RA FLS from TRAIL-induced apoptosis by modulating the expression of the cell survival regulators p21, XIAP, Mcl-1 and RIP. Moreover, we found that not only TRAIL-induced apoptosis, but also TRAIL-triggered proliferation in RA FLS is mediated by caspases with a crucial role for caspase 8. TRAIL was found to induce degradation of p21 and p27 that was caspase-dependent, but independent of the ERK, p38 and PI3 kinase/Akt-signaling pathways. The finding that TRAIL-triggered proliferation and apoptosis share intracellular routes has to be taken in consideration in defining therapeutic strategies on the basis of the administration of TRAIL.

Cell Death and Differentiation (2009) 16, 1227-1237; doi:10.1038/cdd.2009.38; published online 1 May 2009

In recent years, considerable attention has been focused on the potential benefits of tumor necrosis factor (TNF)-related apoptosis-inducing ligand (TRAIL) in cancer therapy, as a broad range of cancer cells are sensitive to TRAIL-induced apoptosis (reviewed in $^{1}$ ). In addition, the use of TRAIL in combination with chemotherapeutic agents or irradiation strengthens its apoptotic effects and frequently sensitizes the otherwise TRAIL-resistant tumor cells. It is important that TRAIL does not seem to be toxic to normal cells, as TRAIL exposure shows no toxic side effects of therapeutically relevant doses in primates.

Tumor necrosis factor (TNF)-related apoptosis-inducing ligand can interact with five different receptors: four membrane-anchored receptors TRAIL-R1 (DR4), TRAIL-R2 (DR5), TRAIL-R3 (DcR1) and TRAIL-R4 (DcR2) and a soluble decoy receptor osteoprotegerin. The receptors TRAIL-R1 and -R2 contain an intracellular cytoplasmic sequence motif, known as the death domain (DD), and can induce apoptosis through activation of caspases (reviewed $i^{2}$ ). Nevertheless, TRAIL-receptors R1 and R2 not only trigger apoptosis, but also proliferation and differentiation depending on the cell type (reviewed $\mathrm{in}^{2}$ ). This phenomenon has been described for several other members of the TNF family and it is thought that one pathway potentially pre-dominates, but that a build-up of intracellular regulators can flick the switch from cell death to proliferation and vice versa. ${ }^{2,3}$ For example, TRAIL has been shown to promote cell survival and proliferation of endothelial and vascular smooth muscle cells $s^{4,5}$ and to regulate erythroid and monocytic maturation. ${ }^{6}$

Evidence is accumulating that TRAIL has multiple effects also on tumor cells. For example, Ehrhardt et al. ${ }^{7}$ analyzed the effect of TRAIL on primary cells of children with untreated acute leukemia. They observed that TRAIL induced apoptosis in only $50 \%$ of the leukemia cell samples tested, but survival or proliferation in the remaining samples. ${ }^{7}$ Concurring with this report is a study describing that the effect of TRAIL on leukemia cells can be either pro-apoptotic or pro-proliferative. ${ }^{8}$ A more recent publication reported that TRAIL promotes metastasis of human pancreatic ductal adenocarcinoma in $\mathrm{SCID} /$ beige mice. ${ }^{9}$ All these findings challenge the proposed strategy to use TRAIL for targeting tumor cells. To overcome this problem, it has been suggested to sensitize tumor cells for TRAIL-induced apoptosis by blocking the proliferative signaling pathways. For this, it is essential to characterize the respective pathways triggered by TRAIL.

Rheumatoid arthritis (RA) is characterized by the pseudotumoral expansion of synovial tissue that lines the capsule of a joint and is composed of differentiated macrophages and fibroblast-like synoviocytes (FLS). The FLS play a crucial role in the physiopathology of RA, as they invade and finally

\footnotetext{
${ }^{1}$ Institut de Génétique Moléculaire de Montpellier, CNRS-UMR5535, Montpellier, France; ${ }^{2}$ Service d'Immuno-Rhumatologie et Université Montpellier 1, Montpellier, France and ${ }^{3}$ Service chirurgie de la main et du membre supérieur, CHU Lapeyronie, Montpellier, France

*Corresponding author: M Hahne, Institut de Génétique Moléculaire de Montpellier, CNRS-UMR5535, 1919 Route de Mende, 34293 Montpellier Cedex 5, France. Tel: + 33 (0) 467613639; Fax: + 33 (0) 467040231. E-mail: michael.hahne@igmm.cnrs.fr

${ }^{4}$ These authors share senior authorship.

Keywords: rheumatoid arthritis; TRAIL; synovial fibroblasts; proliferation; apoptosis

Abbreviations: TRAIL, TNF-related apoptosis inducing ligand; TRAIL-R, TRAIL-receptor; DD, death domain; SCID, Severe combined immunodeficiency; FLS, fibroblast-like synoviocytes; RA, rheumatoid arthritis; S.E.M., standard error of the mean; DISC, death-inducing signaling complex

Received 10.10.08; revised 27.2.09; accepted 16.3.09; Edited by SJ Martin; published online 01.5 .09
} 
destroy the joint structure. The proliferation of RA FLS is considered to be pseudo-tumoral, as RA FLS proliferate in an anchorage-independent manner, lack contact inhibition, and express oncogenes and cell cycle proteins indicative of transformation. ${ }^{10}$ Several primary tumors are difficult to maintain in cell cultures and require special conditions. In contrast, the tumor-like features exhibited by RA FLS can be easily mimicked in vitro, as RA FLS grow under standard cell culture conditions. This, together with our access to synovial tissue isolated from the RA patients, led us to choose RA FLS as the cellular model to investigate the therapeutic potential of TRAIL on tumor tissues.

We have described earlier that TRAIL induces apoptosis only in a subset of RA FLS that is followed by an induction of proliferation in the surviving cells. ${ }^{11}$ This suggests that FLS of RA patients consists of different subpopulations according to their different TRAIL responses. The observed dual functionality of TRAIL on RA FLS concurs with the earlier reported pleiotropic responses of TRAIL in primary human tumor cells and underlines that the pseudo-tumoral expansion of RA FLS is a suitable model to characterize the signaling pathways triggered by TRAIL. The molecular differences of the signaling pathways mediating TRAIL-induced apoptosis and proliferation are still poorly understood. The aim of this study was to better understand the molecular basis of TRAIL-triggered signaling pathways in RA FLS.

\section{Results}

The PI3 kinase/Akt-signaling pathway, but not the MAP kinases ERK and p38, protect RA FLS from TRAILinduced apoptosis. We have described earlier that TRAIL activates the MAP kinases ERK and p38, as well as the serine/ threonine kinase Akt, with kinetics similar to that observed for TNF- $\alpha$-driven proliferation of RA FLS. ${ }^{11}$ To test whether either of these pathways is also implicated in TRAIL-induced apoptosis, we used specific inhibitors targeting $\mathrm{PI} 3$ kinase (LY294002), ERK1/2 (PD98059) and p38 (SB203580). For this, RA FLS from five different patients were pretreated with the specific inhibitors at different concentrations or with solvent (DMSO) alone, for 45 min before the addition of TRAIL (1 nM). TRAIL (1 nM) was sufficient to induce maximal proliferation and apoptosis in RA FLS (Figure 1). Proliferation of RA FLS was determined by $\left[{ }^{3} \mathrm{H}\right]$ thymidine incorporation after $72 \mathrm{~h}$ of TRAIL exposure, revealing that addition of each kinase inhibitor diminished TRAIL-induced proliferation in a dosedependent manner (data not shown), in agreement with our earlier findings. ${ }^{11}$ To measure cell death, cells were treated for $24 \mathrm{~h}$ with TRAIL and analyzed by Annexin V staining/TO-PRO3 uptake. Addition of the PI3 kinase inhibitor LY294002 sensitized RA FLS towards TRAIL-induced apoptosis in a dose-dependent manner, whereas ERK and p38 inhibitors displayed no significant effect on cell viability (Figure 2a). This
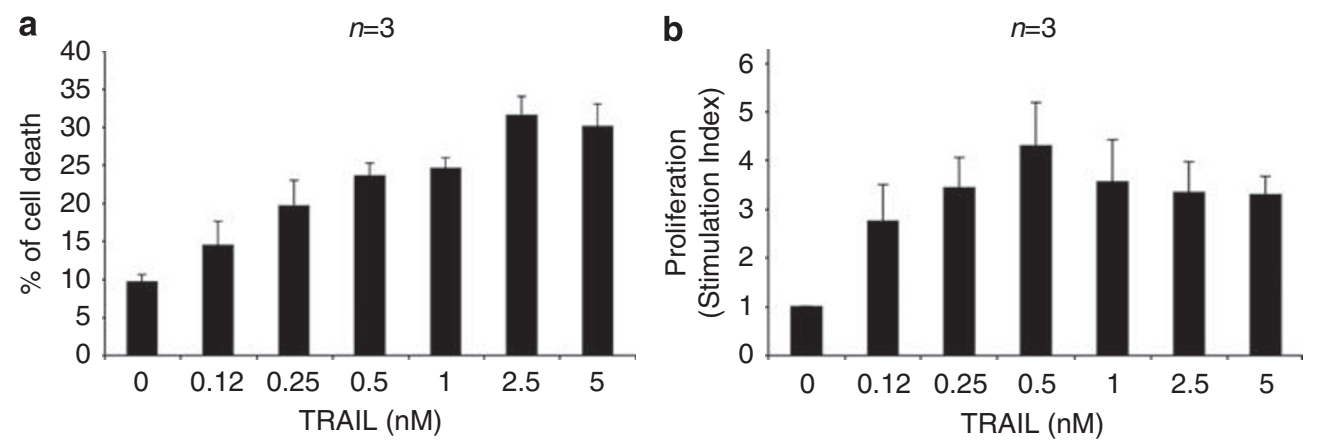

Figure 1 Titration of TRAIL concentrations for induction of apoptosis and proliferation on RA FLS. Cells were treated with TRAIL at the indicated concentrations and analyzed by FACS for apoptosis after $24 \mathrm{~h}$ using Annexin V binding and TOPRO-3 uptake (a) or proliferation measured by $\left[{ }^{3} \mathrm{H}\right]$ thymidine incorporation (b). Results represent proliferation of RA FLS after $72 \mathrm{~h}$ on treatment and are expressed as stimulation index (arithmetic mean of $\mathrm{cpm}$ from quadruplicate of stimulated culture/arithmetic mean of cpm from quadruplicate of non-stimulated culture). For apoptosis experiments, results are expressed as the $\%$ of total cell death (Annexin $+/ T O P R O-3+)$. Data from three RA donors are represented as mean \pm S.E.M.

\footnotetext{
Figure 2 The PI3 kinase/Akt-signaling pathway protects RA FLS from TRAIL-induced apoptosis. (a) The PI3 kinase inhibitor LY294002 increases TRAIL-induced apoptosis in RA FLS. RA FLS were untreated (NS) or pre-treated for 45 min with inhibitors (In) for PI3 kinase (LY294002), ERK 1/2 (PD98059), p38 MAPK (SB203580) at the indicated concentrations or DMSO alone and then stimulated with TRAIL ( $1 \mathrm{nM})$ for $24 \mathrm{~h}$. Cells were analyzed by FACS for apoptosis using Annexin V binding and TOPRO-3 uptake. Data from five RA donors are represented as mean \pm S.E.M. Asterisks (*) indicate $P$-values $<0.05$ versus cells treated only with TRAIL. (b) The PI 3 kinase inhibitors, wortmannin and PI-103, as well as an inhibitor of Akt increase TRAlL-induced apoptosis in RA FLS. RA FLS were untreated (NS) or pre-treated for 45 min with PI3 kinase inhibitors wortmannin and PI-103 at the indicated concentrations and then stimulated with TRAIL ( $1 \mathrm{nM}$ ) for $24 \mathrm{~h}$. Cells were analyzed by FACS for apoptosis using Annexin V binding and TO-PRO-3 uptake. Data from five RA donors are represented as mean \pm S.E.M. Asterisks $\left(^{*}\right)$ indicate $P$-values $<0.05$ versus cells treated only with TRAlL. (c) Treatment of RA FLS with the PI3 kinase inhibitor LY294002 alters expression levels of p21, Mcl1 and XIAP. RA FLS were treated with LY294002 (20 $\mu \mathrm{M})$ for $6 \mathrm{~h}(\mathrm{p} 27, \mathrm{p} 21)$ or $24 \mathrm{~h}$ (RIP, PTEN, Mcl1 and XIAP) and analyzed by western blotting. Band intensities for p27, p21, RIP, PTEN, Mcl1 and XIAP were normalized to those of $\beta$-actin. Note, that the anti-XIAP antibody detects in addition to the $57 \mathrm{kDa}$ species corresponding to XIAP a non-specific higher molecular weight species of about $63 \mathrm{kDa}$ labeled by an asterisk. Representative western blots are shown obtained by analyzing FLS of at least three different RA donors. The table on the right hand side summarizes the mean protein expression levels detected in the different experiments performed. (d) Treatment of TRAIL-stimulated RA FLS with the PI3 kinase inhibitor LY294002 alters expression levels of p21, Mcl1 and XIAP. RA FLS were treated for $6 \mathrm{~h}$ with LY294002 $(20 \mu \mathrm{M})$ and analyzed as described above. The table on the right hand side summarizes the mean protein expression levels detected after 6 and $24 \mathrm{~h}$ of TRAlL stimulation in the different experiments performed
} 
a

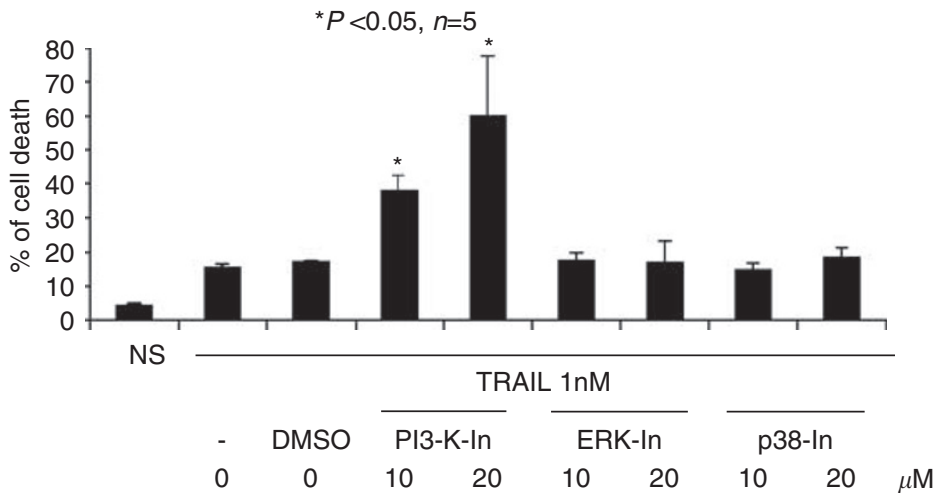

b

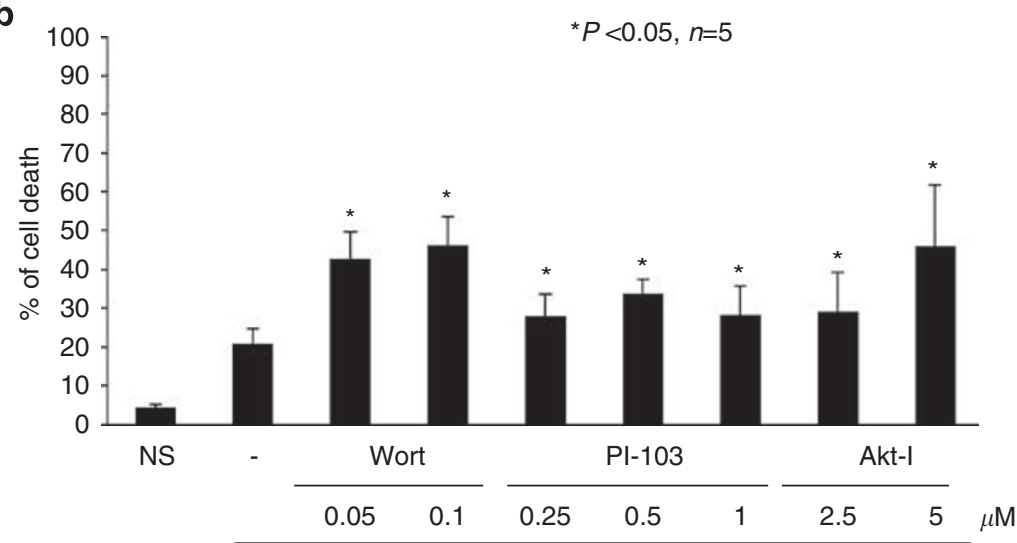

c

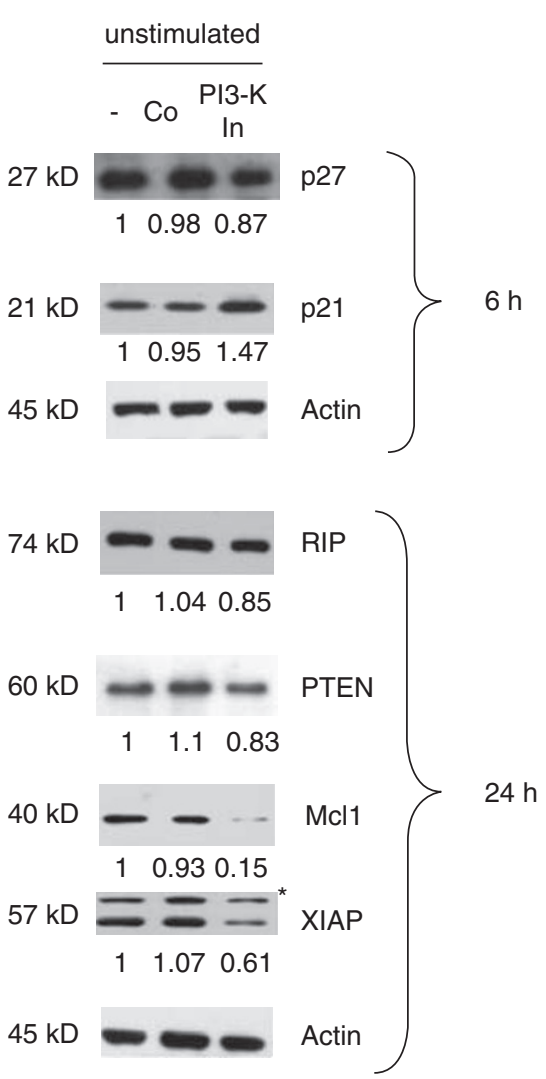

TRAIL 1nM

Mean \pm S.E.M. of protein expression in PI3-K-In treated cells versus untreated cells (after normalization with $\beta$-actin)

\begin{tabular}{|c|c|c|}
\hline $6 \mathrm{~h}$ & $24 \mathrm{~h}$ & $\begin{array}{c}\text { different } \\
\text { patients tested }\end{array}$ \\
\hline $0.86 \pm 0.15$ & $0.89 \pm 0.22$ & 4 \\
\hline $1.49 \pm 0.25$ & $1.09 \pm 0.12$ & 6 \\
\hline $0.98 \pm 0.1$ & $0.69 \pm 0.08$ & 5 \\
\hline $0.97 \pm 0.03$ & $0.83 \pm 0.06$ & 3 \\
\hline $1.31 \pm 0.13$ & $0.52 \pm 0.2$ & 4 \\
\hline $1.07 \pm 0.16$ & $0.7 \pm 0.06$ & 4 \\
\hline
\end{tabular}

Number of RAFLS from different

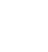


d

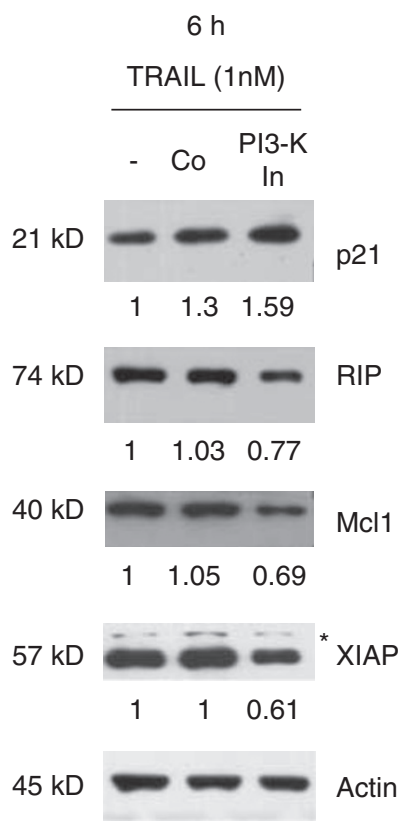

\begin{tabular}{|c|c|c|}
\hline \multicolumn{2}{|c|}{$\begin{array}{c}\text { Mean } \pm \text { S.E.M. of protein expression in } \\
\text { PI3-K-In/TRAIL treated cells versus } \\
\text { TRAIL treated cells (after } \\
\text { normalization with } \beta \text {-actin) }\end{array}$} & \multirow[t]{2}{*}{$\begin{array}{l}\text { Number of } \\
\text { RAFLS from } \\
\text { different patients } \\
\text { tested }\end{array}$} \\
\hline $6 \mathrm{~h}$ & $24 \mathrm{~h}$ & \\
\hline $1.44 \pm 0.26$ & $0.77 \pm 0.37$ & 6 \\
\hline $0.76 \pm 0.18$ & $0.44 \pm 0.11$ & 5 \\
\hline $0.66 \pm 0.16$ & $0.39 \pm 0.19$ & 3 \\
\hline $0.58 \pm 0.0$ & $0.36 \pm 0.1$ & 4 \\
\hline
\end{tabular}

Figure 2 Continued.

sensitization was not because of an altered expression pattern of TRAIL receptors 1 and 2 (data not shown). By using the structurally unrelated $\mathrm{PI} 3$ kinase inhibitors, wortmannin and $\mathrm{PI}$ 103, we could confirm that the observed effect of LY294002 is indeed because of blocking of $\mathrm{PI} 3$ kinase (Figure 2b). In addition, we have used a chemical inhibitor for Akt (protein kinase B), which is activated by $\mathrm{Pl} 3$ kinases, displaying increased TRAIL-induced apoptosis similar to that observed for the PI3 kinase inhibitors (Figure 2b).

We next tested whether exposure of RA FLS to the PI3 kinase inhibitor LY294002 altered the expression levels of well-established regulators of cell survival including XIAP, PTEN, Mcl-1, RIP, p21 and p27. Western blot analysis displayed altered expression levels of XIAP, Mcl-1, RIP and p21 in LY294002-treated RA FLS, whereas expression of p27 and PTEN only moderately decreased (Figure 2c). Expression levels of p21 and p27 were already affected after $6 \mathrm{~h}$ of LY290042 exposure, whereas those of XIAP, PTEN, Mcl-1 and RIP were only observed after $24 \mathrm{~h}$ of treatment. In TRAIL-treated cells, levels of XIAP, Mcl-1 and RIP were already decreased after $6 \mathrm{~h}$ of LY290042 exposure (Figure 2d), suggesting that $\mathrm{PI} 3$ kinase activation may protect these proteins from TRAIL-induced degradation. Noteworthy, p21 levels were elevated after $6 \mathrm{~h}$, but decreased after $24 \mathrm{~h}$ of co-treatment with LY290042 and TRAIL. This observation indicates that PI3 kinase inhibition only temporarily protects TRAIL-induced p21 degradation (see below).

Thus, whereas the ERK, p38 and PI3 kinase/Akt-signaling pathways are all involved in TRAIL-induced proliferation, only $\mathrm{PI} 3$ kinase/Akt protects RA FLS from TRAIL-triggered apoptosis, possibly by modulating the expression levels of p21, XIAP, Mcl-1 and RIP.
Caspases mediate both TRAIL-induced apoptosis as well as proliferation in RA FLS. RA FLS have been shown by us and others to express TRAIL receptors 1 and $2 .{ }^{11-13} \mathrm{It}$ is well established that binding of TRAIL to TRAILR-1 and -2 can induce apoptosis through activation of caspases (reviewed in ${ }^{1}$ ). To analyze the activation of caspases in TRAIL-treated RA FLS, cells were pretreated for $45 \mathrm{~min}$ with the pan-caspase inhibitor z-VAD-fmk or with the control inhibitor z-FA-fmk before the addition of TRAIL. z-VAD-fmktreated RA FLS of different patients were monitored for apoptosis by Annexin V staining/TO-PRO-3 uptake and in parallel for proliferation by $\left[{ }^{3} \mathrm{H}\right]$ thymidine incorporation (Figure $3 a$ and b). As expected, z-VAD-fmk treatment almost completely blocked TRAIL-induced apoptosis even at low concentrations such as $0.5 \mu \mathrm{M}$ (Figure 3a), whereas the control inhibitor z-FA-fmk had no effect on RA FLS survival (data not shown). It is surprising that treatment with z-VAD-fmk also decreased TRAIL-induced proliferation of RA FLS, and the addition of $5 \mu \mathrm{M}$ of z-VAD-fmk almost completely abrogated TRAIL-induced proliferation (Figure $3 b$ ). Similar results were obtained when cells were pretreated with the pan-caspase inhibitor Q-VD-OPh before TRAIL treatment ${ }^{14}$ (data not shown). These data suggest that in RA FLS caspases play a role in both TRAIL-driven apoptosis and proliferation.

We have reported earlier that the cleaved forms of caspases 3,8 and 9 are detectable in cell lysates of RA FLS treated with TRAIL. ${ }^{14}$ To determine their exact contribution to TRAIL-induced apoptosis and proliferation, we used specific inhibitors for each one. All three caspases inhibitors significantly diminished TRAIL-induced apoptosis at $5 \mu \mathrm{M}$, though less efficiently as the pan-caspase inhibitor (Figure 4a). 

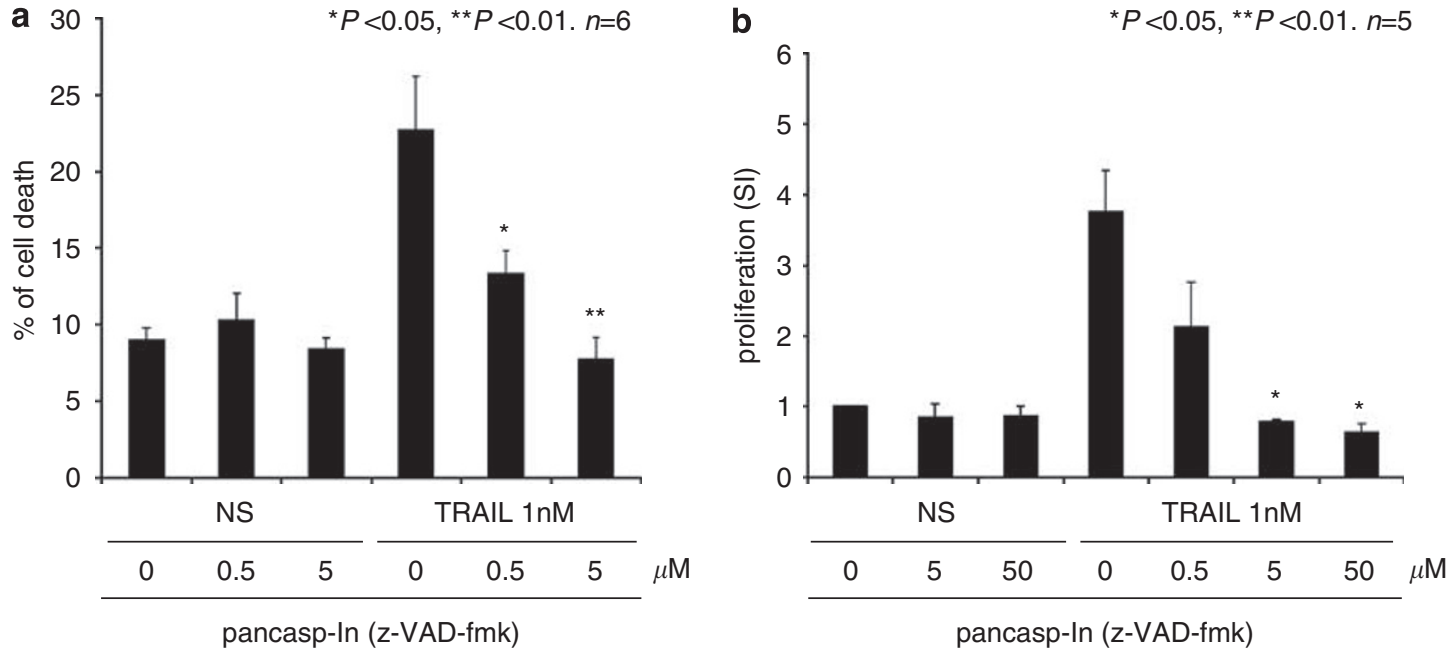

Figure 3 TRAIL-induced cell death and proliferation in RA FLS is caspase-dependent. (a) Cells untreated (NS) or treated for $24 \mathrm{~h}$ with TRAIL in the presence of the pancaspase inhibitor (pancasp-In) z-VAD-fmk were analyzed by FACS for apoptosis using Annexin V binding and TO-PRO-3 uptake. (b) RA FLS were cultured for $72 \mathrm{~h}$ in the absence or presence of TRAIL $(1 \mathrm{nM})$ and together with the indicated concentration of the pancaspe inhibitor $z-V A D$-fmk. Proliferation was assessed using $\left[{ }^{3} \mathrm{H}\right]$ thymidine incorporation and is expressed as stimulation index (see Figure 1). Data from the indicated number of patients $(n)$ are shown as means \pm S.E.M. (NS, non-stimulated); asterisks $\left(^{*}\right)$ indicate $P$-values $<0.05$ and two asterisks $\left(^{* *}\right)$ indicate $P$-values $<0.01$ versus cells treated only with TRAIL

The specific inhibitors for caspases 3 and 8 also modulated TRAIL-induced proliferation (Figure 4b). However, these effects were dependent on the concentration of the respective inhibitor used. Low concentrations of the inhibitors for caspase 3 and 8 increased TRAIL-stimulated proliferation of RA FLS, whereas they decreased proliferation when added at concentration of $50 \mu \mathrm{M}$ (Figure 4b). Blocking of TRAILinduced proliferation was more efficient with the caspase 8 inhibitor, which showed an effect at a concentration of $20 \mu \mathrm{M}$ (Figure 4c). The specific caspase 9 inhibitor had no significant effect on TRAIL-induced proliferation (Figure 4b), but was toxic at a concentration of $50 \mu \mathrm{M}$ (as detected using MTT assay, data not shown). Treatment of RA FLS with the highest non-toxic concentration of the specific caspase 9 inhibitor, that is, $20 \mu \mathrm{M}$, induced a small, but not significant reduction of TRAIL-induced proliferation (Figure 4c).

To further assess the contribution of individual caspases we used small interfering RNAs (siRNA) against caspases 3, 8 and 9 as an additional approach. As shown in Figures $4 \mathrm{~d}-\mathrm{g}$, only siRNA silencing of caspase 8 , but not of caspases 3 and 9, was able to diminish TRAIL-induced apoptosis and proliferation. The efficiency of caspases silencing in RA FLS is shown in Figure $4 \mathrm{~h}$. Taken together, these data indicate that caspases mediate both TRAIL-induced apoptosis as well as proliferation in RA FLS. Caspase 8 in particular seems to play an important role in both the processes.

TRAIL induces caspase-dependent degradation of the cell cycle inhibitors p21 and p27. As described earlier, TRAIL induces RA FLS proliferation through activation of the MAP kinases ERK and p38, as well as the PI3 kinase/Akt pathway. ${ }^{11}$ We therefore tested whether caspases participate in the activation of these pathways. The presence of the pan-caspase inhibitor z-VAD-fmk did not seem to affect TRAIL-induced phosphorylation (and thus activation) of either Akt or the MAP kinases ERK and p38 (Figure 5). However, we did observe that addition of the pancaspase inhibitor significantly induced phosphorylation of MAP kinases ERK and p38, as well as Akt in unstimulated RA FLS. This effect of $z-V A D$-fmk was dose dependent (data not shown). It is worth noting that addition of z-VAD-fmk itself had no effect on survival or proliferation of RA FLS (Figure 3a and b).

As described above (Figure 2d), we had observed that TRAIL treatment seems to alter p21 levels in RA FLS. In fact, a recent report correlated the responses of RA FLS to TRAIL, with the expression levels of the cell cycle regulator $p 21 .{ }^{15} \mathrm{We}$ therefore analyzed the expression levels of $\mathrm{p} 21^{\text {Waf } 1 / \text { Cip } 1}$ and of p27 ${ }^{\text {Kip1 }}$, another important cell cycle regulator, in TRAILtreated RA FLS. Expression levels of p21 and p27 were decreased in cells treated for $24 \mathrm{~h}$ with TRAIL compared with untreated cells. The level of p21 expression decreased already $6 \mathrm{~h}$ after TRAIL exposure (Figure 6a). It is important that the TRAIL-induced decrease of p21 and p27 was inhibited by the presence of the pan-caspase inhibitor zVAD-fmk (Figure 6a). In contrast, inhibitors for PI3-K, ERK and p38 were unable to prevent the TRAIL-dependent degradation of p21 and p27 (Figure 6b). Using specific inhibitors for caspases 3,8 and 9 , we found different capacities of the respective molecules to block the TRAILmediated reduction of p21 and p27 expression (Table 1). The inhibitor for caspase 8 blocked both p21 and p27 degradation in each of the RA FLS tested, whereas the efficiency of caspase 3 and 9 inhibitors varied between RA FLS from different patients (Table 1). In agreement with this, siRNA silencing of caspase 8 was capable to rescue TRAIL-induced p21 and p27 degradation as well (data not shown).

p21 and p27 can be localized in the cytoplasm, as well as in the nucleus. The antibody used for detection of p27 allowed us to detect the cleaved form of p27 at $23 \mathrm{kDa}$ in both the 
cytoplasmic and nuclear fraction of TRAIL-treated RA FLS (Figure 6c). The presence of z-VAD-fmk abrogated the cleavage of $\mathrm{p} 27$, confirming that the TRAIL-triggered cleavage of p27 is caspase dependent (data not shown).

\section{Discussion}

Earlier, we have reported the pleiotropic effect of TRAIL on tumor-like RA FLS by stimulating apoptosis and

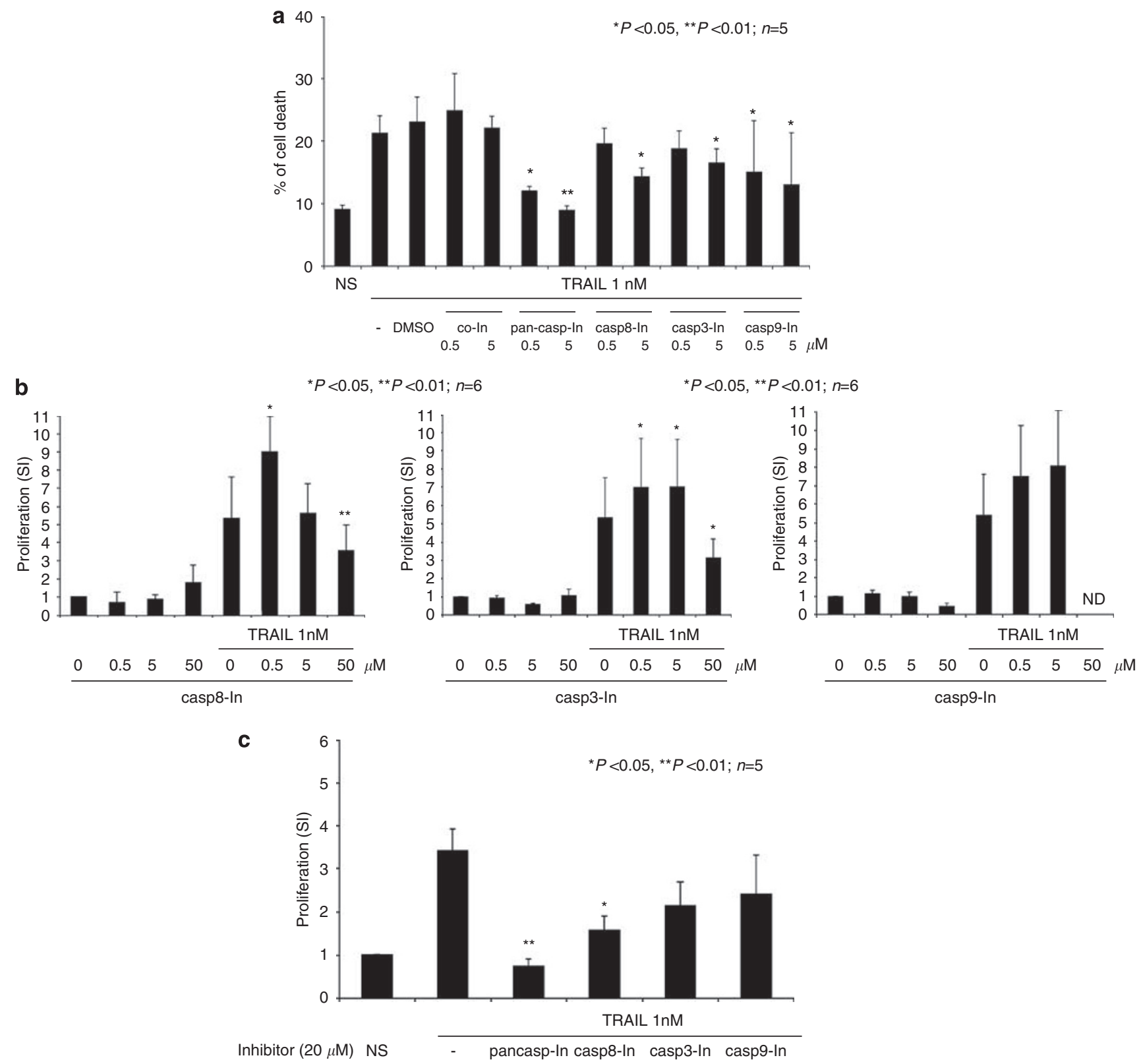

Figure 4 Caspase 8 has an important role in mediating TRAIL-induced apoptosis and proliferation in RA FLS. (a) Effect of specific caspase inhibitors on TRAIL-induced cell death (a). RA FLS were pre-treated with caspase inhibitors (In) or control inhibitor z-FA-fmk (co, control inhibitor) for $1 \mathrm{~h}$ and cultured for $24 \mathrm{~h}$ with TRAIL for the analysis of apoptosis. As controls served cells pre-treated with solvent only (DMSO). ( $b$ and $\mathbf{c}$ ) Effect of specific caspase inhibitors on TRAIL-induced proliferation in RA FLS. Cells were pre-treated with caspase inhibitors (In) (pancasp, pan-caspases inhibitor z-VAD-fmk; casp3, caspase 3 inhibitor z-DVEVD-fmk, casp8, caspase 8 inhibitor z-IETD-fmk, casp9, caspase 9 inhibitor z-LEHD-fmk) or control inhibitor z-FA-fmk (co, control inhibitor) for $1 \mathrm{~h}$ and subsequently cultured in the presence of $1 \mathrm{nM}$ TRAIL for additional $24 \mathrm{~h}$ for analysis of apoptosis or $72 \mathrm{~h}$ for determination of proliferation. As controls served cells pre-treated with solvent only (DMSO). Proliferation was assessed using $\left.{ }^{3} \mathrm{H}\right]$ thymidine incorporation. Results are expressed as stimulation index (see Figure 1). Of note, RA FLS could not be treated with $50 \mu \mathrm{M}$ of the caspase 9 inhibitor because of toxicity (ND). Data from the indicated number of patients $(n)$ were averaged and shown as means \pm S.E.M. (NS, non-stimulated RA FLS); asterisks $\left({ }^{*}\right)$ indicate $P$-values $<0.05$ and two asterisks $\left(^{* *}\right)$ indicate $P$-values $<0.01$ versus cells treated only with TRAIL. $(\mathbf{d}-\mathbf{g})$ Effect of caspase silencing by siRNA on TRAIL-induced cell death (d, $\mathbf{f}$ ) and proliferation $(\mathbf{e}$ and g) in RA FLS. Cells were transfected with $100 \mathrm{nM}$ of caspases 3,8 siRNA and $60 \mathrm{nM}$ of caspases 9 siRNA or control siRNA nucleotides to silence either caspase 3,8 or 9. After $48 \mathrm{~h}$ cells were treated with $1 \mathrm{nM}$ TRAIL for an additional $24 \mathrm{~h}$ and subsequently analyzed for apoptosis and proliferation, as described under Figure 1. (h) Efficiency of caspase silencing for the respective caspase was verified using western blot analysis. Blots were probed with specific antibodies for either caspase 3,8 or 9 and subsequently scanned and quantified using $\mathrm{NIH}$ image software. Band intensities for the respective caspase were normalized to the corresponding band intensities of control siRNA transfected cells. One representative analysis is shown 

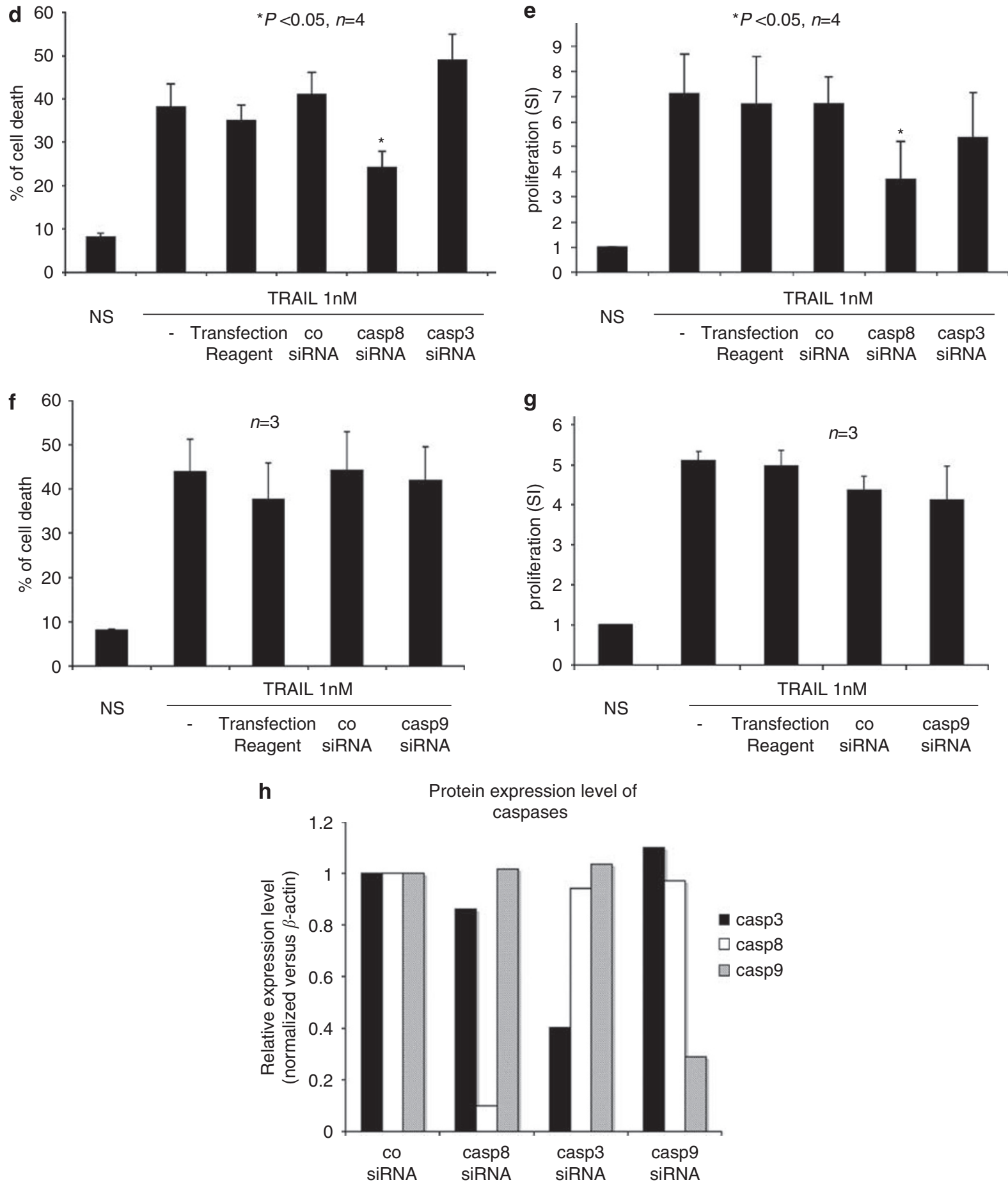

Figure 4 Continued

proliferation. ${ }^{11}$ Our finding differs from earlier reports describing that TRAIL has a protective role in the collagen-induced mouse model of arthritis by blocking the proliferation of synovial cells. ${ }^{16,17}$ This discrepancy could reflect the different pathogenic mechanisms between RA in the joints of patients and the respective mouse model. Moreover, the organization of TRAIL signaling between man and mouse seems to be different, as only one membrane-anchored TRAIL receptor and two soluble decoy receptors have been identified in the mouse. $^{18}$

We have described that the ERK, p38 and PI3 kinase/Aktsignaling pathways are implicated in TRAIL-induced RA FLS proliferation. ${ }^{11}$ In this study, we aimed to further characterize the TRAIL-induced signaling pathways in RA FLS. By using 
Phosphorylated p38 $(n=5)$

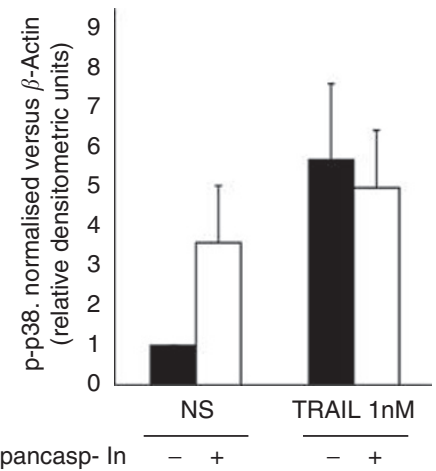

$(10 \mu \mathrm{M})$

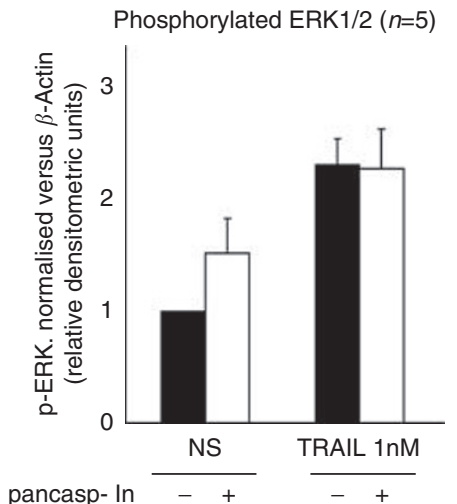

$(10 \mu \mathrm{M})$

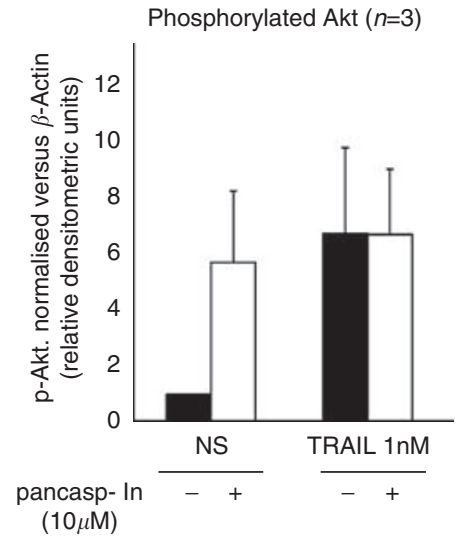

Figure 5 Activation of MAP kinases p38 and ERK1/2 and Akt is caspase-independent. Cell lysates of non-stimulated (NS) and TRAlL-stimulated (10 min) RA FLS ( $n=5$ ) in the absence or presence of the pan-caspase inhibitor (pancasp-In) Z-VAD-fmk were analyzed by western blotting for phospho-p38 MAP kinase, phospho-ERK1/2 kinases and phospho-Akt. Each blot was stripped and reprobed with a mouse anti-human $\beta$-actin antibody. Blots were scanned and quantified using NIH image software. Band intensities for phospho-Akt, phospho-p38 MAP and -ERK1/2 kinases were normalized to the corresponding band intensities for $\beta$-actin. Data from five RA donors were averaged and are represented as mean \pm S.E.M.

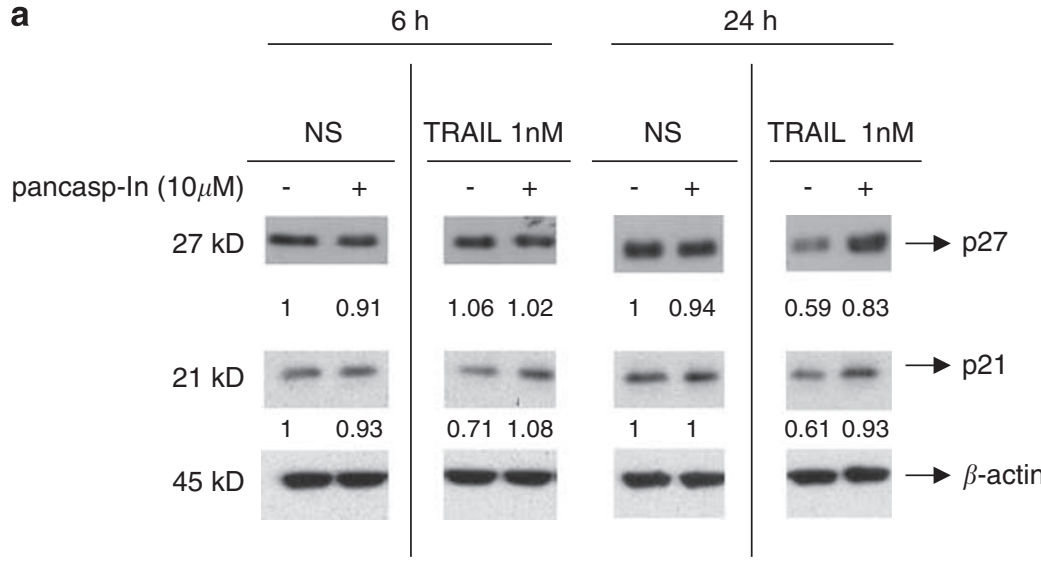

b

$1:$ no $\ln$

2: pancasp-In

3: PI3-K-In

4: ERK-In

5: p38-In
$24 \mathrm{~h}$

\begin{tabular}{llll}
\multicolumn{4}{c}{ NS } \\
\hline 12 & 3 & 4
\end{tabular}

TRAIL (1nM)

$27 \mathrm{kD}$

$21 \mathrm{kD}$

$45 \mathrm{kD}$

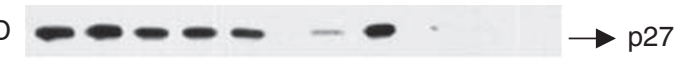

$\rightarrow \mathrm{p} 21$

$\rightarrow \beta$-actin

C

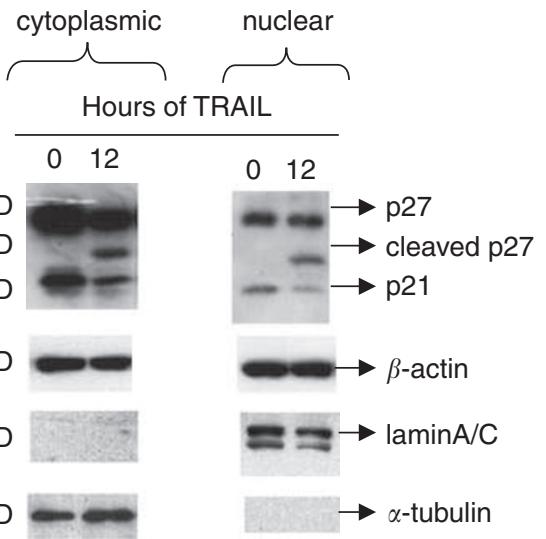

Figure 6 TRAIL induces caspase-dependent degradation of the cell cycle inhibitors p21 and p27 in RA FLS. (a) RA FLS were stimulated for $6 \mathrm{~h}$ or $24 \mathrm{~h}$ with TRAIL ( $1 \mathrm{nM}$ ) in the presence of $20 \mu \mathrm{M}$ of the pan-caspase inhibitor z-VAD-fmk or control inhibitor z-FA-fmk. (b) RA FLS were stimulated for $24 \mathrm{~h}$ with TRAIL ( $1 \mathrm{nM}$ ) in the presence of $10 \mu \mathrm{M}$ of the pan-caspase inhibitor (pancasp-In) z-VAD-fmk or of the specific inhibitors (In) for PI3 kinase (LY294002), and $20 \mu \mathrm{M}$ of the specific inhibitors (In) for ERK 1/2 (PD98059), p38 MAPK (SB203580). Cell lysates were analyzed by immunoblot for p21 and p27 expression. The same blot was stripped and reprobed with a mouse anti-human $\beta$-actin antibody to confirm equal loading. Band intensities for p21 and p27 were normalized to the corresponding band intensities for $\beta$-actin. One representative immunoblot is shown. (c) RA FLS were stimulated for $12 \mathrm{~h}$ with TRAIL (1 nM) and the cytoplasmic and nuclear fractions of these cells were separately analyzed for p21 and p27 expression by western blot as described under $\mathbf{a}$ and $\mathbf{b}$. Samples were simultaneously analyzed by immunoblot for p21 and p27 expression and reprobed for anti-lamin A/C and antialpha-tubulin 
Table 1 Effect of specific caspase inhibitors on TRAIL-induced degradation of the cell cycle inhibitors p21 and p27

\begin{tabular}{|c|c|c|c|c|c|c|c|c|c|c|}
\hline \multirow[b]{2}{*}{ Inhibitor (20 mM) } & \multicolumn{5}{|c|}{ Rescue of p21 degradation } & \multicolumn{5}{|c|}{ Rescue of p27 degradation } \\
\hline & Casp3 & Casp8 & Casp9 & pancasp & Co & Casp3 & Casp8 & Casp9 & Pancasp & Co \\
\hline RAFLS1 & + & $+1-$ & $+1-$ & + & - & + & + & + & + & - \\
\hline RAFLS2 & $+1-$ & + & - & + & - & $+1-$ & $+1-$ & $+1-$ & + & - \\
\hline RAFLS3 & - & + & $+1-$ & + & - & $+1-$ & + & + & + & - \\
\hline RAFLS4 & $+1-$ & + & $+1-$ & + & - & - & + & $+1-$ & + & - \\
\hline RAFLS5 & - & + & + & + & - & - & + & + & + & - \\
\hline RAFLS6 & + & + & + & + & - & + & + & + & + & - \\
\hline
\end{tabular}

RA FLS were stimulated for $24 \mathrm{~h}$ with TRAIL $(0.5 \mathrm{nM})$ in the presence of $10 \mu \mathrm{M}$ of the pancaspase inhibitor (pancasp-In) $\mathrm{z}$-VAD-fmk or specific inhibitors for caspase 3 , 8 or 9 . Cell lysates were analyzed by immunoblot for $\mathrm{p} 21$ and p27 expression. The same blot was stripped and reprobed with a mouse anti-human $\beta$-actin antibody and band intensities for p21 and p27 were normalized to the corresponding band intensities for $\beta$-actin. Relative efficiency of the respective inhibitor was classified as no rescue $(-)$, partial rescue $(+/-)$ or total rescue $(+)$.

specific protein kinase inhibitors, we found that the PI3 kinase/ Akt-signaling pathway, but not the MAP kinases ERK and p38, protects RA FLS from TRAIL-induced apoptosis. A similar observation has been made in glioblastoma cells by Opel et al. ${ }^{19}$ These authors reported that PI3K inhibition significantly enhances apoptosis triggered by TRAIL in glioblastoma cells. ${ }^{19}$

Blocking of the PI3 kinase/Akt-signaling pathway in RA FLS was associated with decreased expression of the antiapoptotic proteins $\mathrm{Mcl}-1, \mathrm{XIAP}$ and RIP and an increased expression of the cell cycle inhibitor p2 $1^{\text {Waf1/Cip1 }}$. This finding is in agreement with an earlier report describing that Akt regulates the stability of XIAP, and thus suggesting that XIAP modulates the effect of Akt on cell survival of ovarian cancer cells. ${ }^{20}$ Moreover, it has been described that Akt can modulate the activity of p21 and p27 in blocking the cell cycle. ${ }^{21}$ Our data indicate that the PI3 kinase inhibitor LY290042 modulates the expression levels of the cell cycle inhibitor p21, and thus sensitizes RA FLS to TRAIL-induced apoptosis. A similar observation was made for bladder and prostate cancer cells, as p21 accumulation sensitized these cells to TRAIL-induced apoptosis. $^{22}$

Multiple effects of TRAIL have been earlier reported in human carcinoma cell lines. ${ }^{23}$ Low concentrations of TRAIL $(1 \mathrm{ng} / \mathrm{ml})$ were found to preferentially induce proliferation in human carcinoma cells. At higher concentrations $(100 \mathrm{ng} / \mathrm{ml})$, the situation was more complex, as cell populations responded with either apoptosis, senescence or proliferation. We observed a maximal effect for both apoptosis and proliferation of RA FLS at a TRAIL concentration of $1 \mathrm{nM}$ $(20 \mathrm{ng} / \mathrm{ml})$ that was maintained using higher concentrations (up to $10 \mathrm{nM}$ ) of TRAIL. TRAIL-induced apoptosis seems not to be a prerequisite for proliferation, as conditioned supernatant taken from apoptotic RA FLS did not induce proliferation when transferred to other cells (data not shown). This is in line with our observation that RA FLS from some patients are nearly resistant to TRAIL-induced apoptosis, but sensitive to TRAIL-induced proliferation (data not shown).

RA FLS express TRAIL receptors 1 and 2 , which contain an intracellular cytoplasmic sequence motif, known as the DD. ${ }^{11}$ Triggering of TRAIL receptor 1 and 2 results in receptor trimerisation, clustering of the receptor DD and subsequent recruitment of various intracellular molecules, including the dual adapter molecule FADD (Fas-associated DD, also known as Mort1) and the initiator procaspase-8. This complex of interacting proteins is referred to as the death-inducing signaling complex (DISC) because of the original assumption that the main physiological role of FADD-binding death receptors is to trigger apoptosis. However, recent work has shown multiple non-apoptotic activities of these receptors reflecting different signaling components of the DISC. ${ }^{2}$ For example, caspases are known to play essential roles in apoptosis and inflammation, but reports are accumulating that caspases can also have other functions. ${ }^{24,25}$ These nonapoptotic functions of caspases can be mediated by both activated caspases as well as by their prodomains. ${ }^{25}$ For instance, it is by now well established that caspase 8 has an essential role in lymphocyte proliferation in response to antigen stimulation. ${ }^{26}$ Caspase 8 also seems to play a role in cell adhesion and motility. ${ }^{27}$

In our study, we found definitive evidence that caspases are at the crux of both TRAIL-induced apoptosis and proliferation of RA FLS, as a pan-caspase inhibitor blocked both cellular responses. The use of specific caspase inhibitors suggested an involvement of caspases 3, 8 and 9 in TRAIL-induced apoptosis, and of caspases 3 and 8 in TRAIL-induced proliferation. This concurs with our earlier described observation that TRAIL induces cleavage of caspases 3, 8 and 9 in RA FLS. ${ }^{14}$ Using RNA silencing, we found that caspase 8 is required for both TRAIL-induced apoptosis and proliferation.

Numerous different substrates for caspases have been identified, including kinases. ${ }^{28}$ As TRAIL-induced proliferation of RA FLS is mediated by MAP kinases or Akt, we tested whether activation of these kinases is a caspase-dependent process. We could not detect altered activation of MAP kinases or Akt in the presence of a pan-caspase inhibitor, but observed that the inhibitor significantly induced phosphorylation of MAP kinases ERK and p38, as well as Akt in unstimulated RA FLS. As the presence of z-VAD-fmk does not influence survival or proliferation in RA FLS, we conclude that additional signal(s) are required to stimulate their proliferation (Figure 7).

It has been reported that caspases can cleave cell-cycle inhibitors such as p21 and p27. ${ }^{25,29}$ Both proteins are involved in the negative regulation of $\mathrm{G} 1 / \mathrm{S}$ progression in response to $\mathrm{a}$ number of anti-proliferative signals. ${ }^{30}$ Here, we describe TRAIL-induced p21 and p27 degradation and report that this degradation is caspase-dependent, as z-VAD-fmk, a pancaspase inhibitor restores initial level of expression. It is of note that TRAIL-triggered degradation of $\mathrm{p} 21$ and p27 was not altered by the presence of specific inhibitors for PI3-K, ERK 


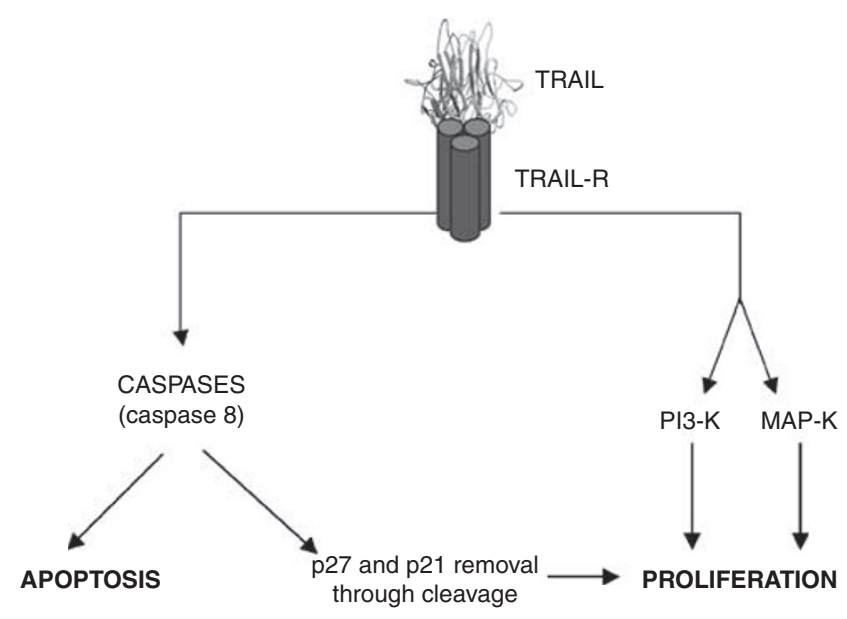

Figure 7 Model of TRAIL-induced signaling in RA FLS. Caspases and PI3 kinase and/or MAP kinases act synergistically to mediate TRAlL-induced proliferation in RA FLS. It is of note that only PI3 kinase, but not MAP kinases, are capable in blocking TRAIL-induced apoptosis

and p38 at concentrations that were sufficient to block TRAILinduced proliferation (data not shown and Morel et al. ${ }^{11}$ ). Thus, the TRAIL-induced degradation of p21 and p27 in RA FLS seems to be a caspase-dependent event, but independent of ERK, p38 and PI3 kinase/Akt-signaling pathways. Our results suggest that caspases act synergistically with $\mathrm{PI} 3$ kinase and/or MAP kinases to mediate TRAIL-induced proliferation in RA FLS.

p21 and p27 have been associated with both apoptosis and proliferation, depending on the cell type. ${ }^{30}$ We observed that RA FLS cells from certain patients are nearly insensitive to apoptosis when exposed to TRAIL, but responded with increased proliferation when compared with untreated cells (data not shown). RA FLS from these patients therefore represent a rather homogenous cell population according to their modulation by TRAIL. Addition of a pan-caspase inhibitor to these cells decreased TRAIL-induced proliferation and degradation of the cell cycle inhibitors p21 and p27 (data not shown). It therefore seems that decreased expression levels of p21 and p27 favor proliferation in RA FLS. A similar conclusion was earlier drawn by Jungel et al., who described a correlation of $p 21$ expression levels with cell viability in TRAILtreated RA FLS. These authors found that upregulation of $p 21$ induced by trichostatin $A$, an inhibitor of histone deacetylases, led to cell cycle arrest and decreased proliferation of RA FLS. ${ }^{15}$ In line with this finding is our observation that nocodazole-induced cell cycle arrest sensitizes RA FLS for TRAIL-induced apoptosis (data not shown).

In this report, we describe that TRAIL-induced apoptosis and proliferation of RA FLS is mediated by caspases and with a crucial role for caspase 8 . The finding that caspase 8 is implicated in TRAIL-induced proliferation in tumor-like RA FLS is to our knowledge the first report associating caspase 8 with proliferation of non-hematopoietic cells.

\section{Materials and Methods}

Reagents. Recombinant human TRAIL was purchased from R\&D Systems (Lille, France). The specific chemical inhibitors LY294002 (PI3 kinase),
PD98059 (ERK1/2) and SB203580 (p38) were purchased from Euromedex (Souffelweyersheim, France), the PI3 kinase inhibitors wortmannin was obtained from Sigma (St Quentin Fallavier, France) and Pl-103 from Cayman Chemical (Ann Arbor, MI, USA) and the Akt Inhibitor VIII was obtained from Calbiochem (Meudon, France). All inhibitors were dissolved in DMSO. Pan-caspase inhibitors (z-VAD-fmk or Q-VD-OPH), caspase 3 inhibitor (z-DEVD-fmk), caspase 8 inhibitor (z-IETD-fmk), caspase 9 inhibitor (z-LEHD-fmk) and the caspase control inhibitor (z-FA-fmk, specific for cathepsins $B$ and $L$ ) were purchased from R\&D Systems (Lille) or from MBL (Woburn, MA, USA) and were dissolved at $20 \mathrm{mM}$ in DMSO. Anti-phospho-Akt was obtained from Cell Signaling (Denver, CO, USA), peroxidase-conjugated secondary antibodies were purchased from Sigma (St Quentin Fallavier) and all other antibodies were obtained from Beckton Dickinson Bioscience Pharmingen (Le Pont-de-Claix, France). The anti-lamin A/C antibody was kindly provided by $\mathrm{Dr}$. Wodrich (CNRS-UMR 5234, Bordeaux, France). The monoclonal antibody $12 \mathrm{G} 10$ against anti-alpha-tubulin developed by J Frankel and M Nelson was obtained from the Developmental Studies Hybridoma Bank developed under the auspices of the $\mathrm{NICHD}$ and maintained by the University of lowa.

Preparation of fibroblast-like synoviocytes of rheumatoid arthritis patients. Fibroblasts were isolated from synovium obtained from patients meeting the American College of Rheumatology criteria for RA (revised 1987), who had undergone surgery for synovectomy or total joint replacement surgery. ${ }^{31}$ Fresh synovial tissues were broken down and digested in a solution of dispase $(2.4 \mathrm{mg} / \mathrm{ml})$ (Gibco, Cergy Pontoise, France), collagenase $(250 \mathrm{U} / \mathrm{ml})$ (Sigma) and DNAse $(10000 \mathrm{U} / \mathrm{ml})$ (Calbiochem, Fontenay sous Bois, France). Synovial fibroblasts were cultured in RPMI- 1640 supplemented with $10 \%$ fetal calf serum (FCS). Cells were used at passage 4-10, when they constitute a homogeneous population of fibroblasts. On reaching confluence, the cells were passaged by brief trypsinization. For experimentation, the FCS in the media was progressively decreased from 10 to $1 \%$, with final starvation for $12 \mathrm{~h}$ in RPMI media containing $1 \%$ FCS, as described earlier ${ }^{11}$.

Cell proliferation assay. Proliferation was evaluated by measuring DNA synthesis as assessed by incorporation of tritiated $\left[{ }^{3} \mathrm{H}\right]$ thymidine. FLS were seeded in 96-well flat-bottom culture plates at a density of $1 \times 10^{4}$ cells/well. Cells were cultured in RPMI with decreasing concentration of FCS (10 and 5\%) and then synchronized for $24 \mathrm{~h}$ with RPMI and $1 \% \mathrm{FCS}$. FLS were stimulated with TRAIL for $72 \mathrm{~h}$. Each condition was tested in triplicate. Cells were pulsed with $\left[{ }^{3} \mathrm{H}\right]$ thymidine $(1 \mu \mathrm{Ci} /$ well) for $24 \mathrm{~h}$. FLS were then lysed using a round of freeze-thaw cycle and then transferred onto a membrane filter using Harvester 96 (TOMTEC, Hamdem, $\mathrm{CT}$, USA). $\left[{ }^{3} \mathrm{H}\right]$ thymidine incorporated into DNA was quantified using a scintillation counter 1450 MicroBeta Trilux (Wallac, Freiburg, Germany). For experiments with protein kinases or caspases inhibitors, FLS were pre-incubated for 45 min with the specific inhibitors (or the solvent DMSO alone), and then cultured with or without TRAIL ( $1 \mathrm{nM}$ ). Similar results were obtained using specific caspase inhibitors from two different manufacturers. None of the employed chemical inhibitors affected cell survival, if not stated otherwise. Results represent proliferation of RA FLS after $72 \mathrm{~h}$ on treatment and are expressed as stimulation index (SI) (arithmetic mean of cpm from quadruplicate of stimulated culture/arithmetic mean of cpm from quadruplicate of non-stimulated culture).

Analysis of apoptosis. Apoptotic RA FLS were identified by re-suspending $1 \times 10^{5}$ cells in $100 \mu$ l Annexin V Binding buffer containing $1 \mu$ l of Annexin V-FITC (Roche Diagnostic, Meylan, France) for $15 \mathrm{~min}$ at room temperature. On addition of TOPRO-3 $(1: 2000)$, cells were analyzed by flow cytometry (FACSCalibur, Beckton Dickinson, Le Pont-de-Claix). Results are expressed as the \% of total cell death (Annexin +/TOPRO-3+).

Western blot analysis. Synovial cells were stimulated with TRAIL at indicated concentrations, and the reaction was stopped by plunging on ice. The cells were washed twice with cold PBS, and lysed with lysis buffer (100 mM Tris, pH 7.4, $100 \mathrm{mM} \mathrm{NaCl}, 1 \mathrm{mM}$ EDTA, $1 \mathrm{mM} \mathrm{NaF}, 20 \mathrm{mM} \mathrm{NaP}_{2} \mathrm{O}_{7}, 2 \mathrm{mM} \mathrm{Na}_{3} \mathrm{VO}_{4}, 1 \%$ Triton X-100, 10\% Glycerol, $0.1 \%$ SDS and $0.5 \%$ desoxycholate) and harvested with a cell scraper. For nuclear extraction experiments, cell were lysed with buffer $(10 \mathrm{mM}$ Hepes, $10 \mathrm{mM} \mathrm{KCl}, 10 \mathrm{mM}$ EDTA, $100 \mu \mathrm{M}$ DTT and $0.4 \%$ IGEPAL) and then centrifuged at $14000 \times g$ for 5 min. Pellets containing nuclear fraction were resuspended in lysis buffer. An equal amount of cell lysate was resolved by 10 or $12 \%$ polyacrylamide gel and immunoblot was carried out as described earlier. ${ }^{32}$ Blots were developed, scanned and densitometric signals were determined using 
$\mathrm{NIH}$ image 1.63 software. Data are expressed as arbitrary units after normalization to levels of $\beta$-actin.

Knock down of caspases by siRNA. RA FLS cells were transfected with $100 \mathrm{nM}$ of siRNA targeting caspases 3 and 8 , and of a control siRNA (Eurogentec Angers, France) or $60 \mathrm{nM}$ of siRNA targeting caspase 9 (Santa Cruz Biochemicals, CA, USA). The cells were transfected for $4 \mathrm{~h}$ using Effectene reagent (Quiagen, Courtaboeuf, France). Various time points were analyzed by western blot to determine the point at which we could achieve maximum decreased protein expression. Cells were treated with TRAIL $48 \mathrm{~h}$ after transfection (or $72 \mathrm{~h}$ in the case of caspase 9 siRNA), and then analyzed for apoptosis and proliferation.

Statistical analysis. Results are expressed as the mean \pm standard error of the mean (S.E.M.). Statistical studies were conducted using non-parametric Wilcoxon test (Instat software). $P$-values $<0.05$ were considered statistically significant.

Acknowledgements. This study was supported by a grant from PROA (INSERM) and the Association pour la Recherche sur le Cancer. RA is supported by the Société Française de Rhumatologie (SFR) and MH by the contrat interface no. 05.524-DRV/MC/SS. We thank Dr. Kimberly for critical reading of the paper. We wish to thank Professor Chammas for providing synovial tissues.

1. Wang S, El-Deiry WS. TRAIL and apoptosis induction by TNF-family death receptors Oncogene 2003; 22: 8628-8633.

2. Di Pietro R, Zauli G. Emerging non-apoptotic functions of tumor necrosis factor-related apoptosis-inducing ligand (TRAIL)/Apo2L. J Cell Physiol 2004; 201: 331-340.

3. Screaton $\mathrm{G}, \mathrm{Xu} X N$. T cell life and death signalling via TNF-receptor family members. Curr Opin Immunol 2000; 12: 316-322.

4. Secchiero P, Gonelli A, Carnevale E, Milani D, Pandolfi A, Zella D et al. TRAIL promotes the survival and proliferation of primary human vascular endothelial cells by activating the Akt and ERK pathways. Circulation 2003; 107: 2250-2256.

5. Secchiero P, Zerbinati C, Rimondi E, Corallini F, Milani D, Grill V et al. TRAlL promotes the survival, migration and proliferation of vascular smooth muscle cells. Cell Mol Life Sci 2004; 61: 1965-1974

6. Secchiero P, Melloni E, Heikinheimo M, Mannisto S, Di Pietro R, lacone A et al. TRAIL regulates normal erythroid maturation through an ERK-dependent pathway. Blood 2004; 103: 517-522.

7. Ehrhardt H, Fulda S, Schmid I, Hiscott J, Debatin KM, Jeremias I. TRAIL induced survival and proliferation in cancer cells resistant towards TRAIL-induced apoptosis mediated by NF-kappaB. Oncogene 2003; 22: 3842-3852.

8. Baader E, Toloczko A, Fuchs U, Schmid I, Beltinger C, Ehrhardt $\mathrm{H}$ et al. Tumor necrosis factor-related apoptosis-inducing ligand-mediated proliferation of tumor cells with receptor proximal apoptosis defects. Cancer Res 2005; 65: 7888-7895.

9. Trauzold A, Siegmund D, Schniewind B, Sipos B, Egberts J, Zorenkov D et al. TRAIL promotes metastasis of human pancreatic ductal adenocarcinoma. Oncogene 2006; 25 7434-7439.

10. Firestein GS. Evolving concepts of rheumatoid arthritis. Nature 2003; 423: 356-361

11. Morel J, Audo R, Hahne M, Combe B. Tumor necrosis factor-related apoptosis-inducing ligand (TRAIL) induces rheumatoid arthritis synovial fibroblast proliferation through mitogen-activated protein kinases and phosphatidylinositol 3-kinase/Akt. J Biol Chem 2005; 280: 15709-15718.
12. Ichikawa $\mathrm{K}$, Liu W, Fleck M, Zhang $\mathrm{H}$, Zhao L, Ohtsuka T et al. TRAll-R2 (DR5) mediates apoptosis of synovial fibroblasts in rheumatoid arthritis. J Immunol 2003; 171: 1061-1069.

13. Miranda-Carus ME, Balsa A, Benito-Miguel M, De Ayala CP, Martin-Mola E. Rheumatoid arthritis synovial fluid fibroblasts express TRAIL-R2 (DR5) that is functionally active. Arthritis Rheum 2004; 50: 2786-2793.

14. Audo R, Deschamps V, Hahne M, Combe B, Morel J. Apoptosis is not the major death mechanism induced by celecoxib on rheumatoid arthritis synovial fibroblasts. Arthritis Res Ther 2007; 9: R128.

15. Jungel A, Baresova V, Ospelt C, Simmen BR, Michel BA, Gay RE et al. Trichostatin A sensitises rheumatoid arthritis synovial fibroblasts for TRAIL-induced apoptosis. Ann Rheum Dis 2006; 65: 910-912.

16. Song K, Chen Y, Goke R, Wilmen A, Seidel C, Goke A et al. Tumor necrosis factor-related apoptosis-inducing ligand (TRAIL) is an inhibitor of autoimmune inflammation and cell cycle progression. J Exp Med 2000; 191: 1095-1104.

17. Lamhamedi-Cherradi SE, Zheng SJ, Maguschak KA, Peschon J, Chen YH. Defective thymocyte apoptosis and accelerated autoimmune diseases in TRAIL-/- mice. Nat Immunol 2003; 4: 255-260.

18. Schaefer U, Voloshanenko O, Willen D, Walczak H. TRAIL: a multifunctional cytokine. Front Biosci 2007; 12: 3813-3824.

19. Opel D, Westhoff MA, Bender A, Braun V, Debatin KM, Fulda S. Phosphatidylinositol 3kinase inhibition broadly sensitizes glioblastoma cells to death receptor- and drug-induced apoptosis. Cancer Res 2008; 68: 6271-6280.

20. Dan HC, Sun M, Kaneko S, Feldman RI, Nicosia SV, Wang HG et al. Akt phosphorylation and stabilization of X-linked inhibitor of apoptosis protein (XIAP). J Biol Chem 2004; 279: 5405-5412.

21. Maddika S, Ande SR, Panigrahi S, Paranjothy T, Weglarczyk K, Zuse A et al. Cell survival, cell death and cell cycle pathways are interconnected: implications for cancer therapy. Drug Resist Updat 2007; 10: 13-29.

22. Lashinger LM, Zhu K, Williams SA, Shrader M, Dinney CP, McConkey DJ. Bortezomib abolishes tumor necrosis factor-related apoptosis-inducing ligand resistance via a p21dependent mechanism in human bladder and prostate cancer cells. Cancer Res 2005; 65: 4902-4908.

23. Levina V, Marrangoni AM, Demarco R, Gorelik E, Lokshin AE. Multiple effects of TRAIL in human carcinoma cells: Induction of apoptosis, senescence, proliferation, and cytokine production. Exp Cell Res 2008; 314: 1605-1616.

24. Siegel RM. Caspases at the crossroads of immune-cell life and death. Nat Rev Immunol 2006; 6: 308-317.

25. Lamkanfi M, Festjens N, Declercq W, Vanden Berghe T, Vandenabeele P. Caspases in cell survival, proliferation and differentiation. Cell Death Differ 2007; 14: 44-55.

26. Tang J, Kawadler H, Yang X. Lymphocyte life and death: the caspase-8 connection. Cancer Biol Ther 2005; 4: 700-702.

27. Senft J, Helfer B, Frisch SM. Caspase-8 interacts with the p85 subunit of phosphatidylinositol 3-kinase to regulate cell adhesion and motility. Cancer Res 2007; 67: 11505-11509.

28. Varfolomeev E, Maecker H, Sharp D, Lawrence D, Renz M, Vucic D et al. Molecular determinants of kinase pathway activation by Apo2 ligand/tumor necrosis factor-related apoptosis-inducing ligand. J Biol Chem 2005; 280: 40599-40608.

29. Fischer U, Janicke RU, Schulze-Osthoff K. Many cuts to ruin: a comprehensive update of caspase substrates. Cell Death Differ 2003; 10: 76-100.

30. Coqueret $\mathrm{O}$. New roles for $\mathrm{p} 21$ and $\mathrm{p} 27$ cell-cycle inhibitors: a function for each cell compartment? Trends Cell Biol 2003; 13: 65-70.

31. Arnett FC, Edworthy SM, Bloch DA, McShane DJ, Fries JF, Cooper NS et al. The American Rheumatism Association 1987 revised criteria for the classification of rheumatoid arthritis. Arthritis Rheum 1988; 31: 315-324.

32. Morel JC, Park CC, Zhu K, Kumar P, Ruth JH, Koch AE. Signal transduction pathways involved in rheumatoid arthritis synovial fibroblast interleukin-18-induced vascular cell adhesion molecule-1 expression. J Biol Chem 2002; 277: 34679-34691. 